\title{
Report of an Indian Family with Sengers Syndrome
}

\author{
Bhawana Aggarwal $^{1} \cdot$ Madhulika Kabra $^{1} \cdot$ Neerja Gupta $^{1}$ (D)
}

Received: 22 May 2020 / Accepted: 4 August 2020 / Published online: 27 August 2020

(C) Dr. K C Chaudhuri Foundation 2020

To the Editor: A five-month-old boy presented with congenital cataract and global developmental delay. Antenatal and birth history was uneventful. Anthropometric examination showed normal height and weight with microcephaly (head circumference: $37.5 \mathrm{~cm} ;-3.42 \mathrm{SD}$, WHO standards). On examination bilateral aphakia (post cataract surgery), respiratory distress, hepatomegaly and central hypotonia were noted. Arterial lactate values were elevated to $10-14 \mathrm{mmol} / \mathrm{L}$. Echocardiography showed concentric left ventricular hypertrophy with $25 \%$ ejection fraction. Creatine phosphokinase was $217 \mathrm{U} / \mathrm{L}$ (normal = 20-200 U/L). Thyroid function test, urine gas chromatography/ mass spectrometry and blood tandem mass spectrometry were unremarkable.

Trio whole exome sequencing revealed homozygosity for a novel splice site variant c.1046_1046 + 1dup in acyl glycerol kinase (AGK) in proband and parents were heterozygous for the same. This variant is predicted to disrupt the highly conserved donor splice site of intron 14. In the subsequent pregnancy, prenatal diagnosis was offered and the fetus was unaffected.

Sengers syndrome (MIM 212350) first reported in 1975, is a rare inherited mitochondrial disease with a constellation of findings including congenital cataract, lactic acidosis, cardiomyopathy and skeletal myopathy [1]. Furthermore, the variable severity results in a wide spectrum of presentations, notably from death in early infancy to mild manifestations in adults. $A G K$ gene is implicated in the disease pathogenesis [2]. $A G K$ is located in the mitochondrial inner membrane and is important for the biosynthesis of phospholipids.

To date, about 40 families with Sengers syndrome have been reported in the literature to the best of our knowledge [3]. The reported phenotype-genotype correlation suggests that homozygous nonsense mutations usually manifest with severe forms

Neerja Gupta

neerja17aiims@gmail.com

1 Division of Genetics, Department of Pediatrics, All India Institute of Medical Sciences, New Delhi 110029, India whereas the presence of at least single splice-site mutation results in milder presentations [3, 4]. On the contrary, our case had severe phenotype with novel homozygous splice-site mutations. Similar observations were recently reported [5].

Our case adds to the existing mutation spectrum of the disease, expands the genotype-phenotype correlations and reiterates the importance of genetic diagnosis in the index case to prevent recurrences.

Besides, it emphasizes that Sengers syndrome should be kept as a differential diagnosis in any child presenting with white reflex, especially in association with lactic acidosis and/ or hypertrophic cardiomyopathy.

Acknowledgements The authors acknowledge the patient's family for the cooperation and consent for the publication.

\section{Compliance with Ethical Standards}

Conflict of Interest None.

\section{References}

1. Sengers RC, Trijbels JM, Willems JL, Daniels O, Stadhouders AM. Congenital cataract and mitochondrial myopathy of skeletal and heart muscle associated with lactic acidosis after exercise. J Pediatr. 1975;86:873-80.

2. Mayr JA, Haack TB, Graf E, et al. Lack of the mitochondrial protein acylglycerol kinase causes Sengers syndrome. Am J Hum Genet. 2012;90:314-20.

3. Haghighi A, Haack TB, Atiq M, et al. Sengers syndrome: six novel AGK mutations in seven new families and review of the phenotypic and mutational spectrum of 29 patients. Orphanet J Rare Dis. 2014;9: 119.

4. Aldahmesh MA, Khan AO, Mohamed JY, Alghamdi MH, Alkuraya FS. Identification of a truncation mutation of acylglycerol kinase (AGK) gene in a novel autosomal recessive cataract locus. Hum Mutat. 2012;33:960-2.

5. Khatter S, Puri RD, Bijarnia-Mahay S, et al. Sengers syndrome in Asian Indians- two novel mutations and variant phenotype-genotype correlation. Transl Sci Rare Dis. 2017;2:157-64.

Publisher's Note Springer Nature remains neutral with regard to jurisdictional claims in published maps and institutional affiliations. 